\title{
Modified Strategies for Assembly Technology Selection of a Mechanical Device by Performing Optimization under Uncertainties
}

\author{
Alexandar Ichtev and Lyudmila Baltova
}

\begin{abstract}
In this paper the investigated problem is how to choose assembly technology for particular mechanical device. The selection process is performed by application of optimization strategies in the presence of uncertainties and discreet number of alternative assembly technologies. Six strategies with proposed new optimization criterion are presented and discussed. In this paper, as a main optimization criterion, it is proposed to minimize the combined cost of labour and equipment (with respect to a single manufactured product). In addition to those strategies, in this paper, three new and modified strategies are proposed, which involve certain social aspects in the decision making process. The problem solution is demonstrated on a particular manufacturing problem assemble of a mechanical device (hydraulic gear pump).
\end{abstract}

Index Terms-Optimization strategies, uncertainties, decision making, assembly technology selection.

\section{INTRODUCTION}

A formal criterion can be applied in order to help decision maker to choose the best assembly technology for each particular product. One possible way for performing this task is with an application of an optimization procedure under uncertainties [1]-[20]. The main strategies are summarized in [1], [2]. Traditionally the optimization criterion is maximization of the profits [1], [2]. However, in this paper the emphasis is put on the production part of the problem and the selling portion is not concern. Thus, it is proposed as a main optimization criterion the minimization of combined production costs $(\mathrm{C})$ to be used. By doing so, in this paper as an objective function for the optimization it is proposed:

$$
C(V, P)=f(x) P_{1}+\frac{M}{P_{2}} \rightarrow \min
$$

where $f(x)$ is the minimal time for assembly of a device; $M$ - are the additional material required for productions which include: working area, equipment (installation, operation), lighting, heating, electricity, energy and others. It is assumed that this costs are known in advance. In this problem there are two uncertain components: $P_{1}$ - expected labour cost (salaries and benefits) per operator per hour, which is ranged $\mathrm{P}_{1 \text { min }} \div \mathrm{P}_{1 \text { max }}$ and $\mathrm{P}_{2}$ - expected production volume, which is ranged $\mathrm{P}_{2 \min } \div \mathrm{P}_{2 \max }$. Also there are several possible assembly technologies $\mathrm{V}_{\mathrm{i}}$. In accordance with the objective function (1) the cost of assembling of a device $\mathrm{C}_{\mathrm{i}, \mathrm{j}}$ for each discrete

Alexandar K. Ichtev is with Department of Systems and Control Engineering, the Faculty of Automatics at the Technical University of Sofia - Bulgaria (e-mail: ichtev@tu-sofia.bg).

Lyudmila I. Baltova is with Department of Fundamentals and Technical Means of Design, the Faculty of Mechanical Engineering at the Technical University of Sofia - Bulgaria (e-mail: lbaltova@tu-sofia.bg). alternative $\left(\mathrm{V}_{\mathrm{i}}\right)$ and for each combination $\left(\Theta_{\mathrm{j}}\right)$ of the values of the uncertain parameters are determined.

In accordance with the ideas embodied in the strategy "Europe 2020" in this paper three modified strategies are proposed, in which an essential role is devoted to the social factors: maintaining employment resource, i.e. preserving jobs for the company's skilled workers during the economic crisis.

The paper is organised as follows: in Section II the investigated benchmark example is presented and a discussion is carried out regarding the ranges of the uncertainty parameters and possible assembly technologies; in Section III nine strategies for decision making are presented and results from the application of the benchmark example are presented. The first five of them are known from the literature optimization strategies, but in this paper a new objective function for the optimization is proposed and applied for all of them. The remaining four strategies are modification of the main strategies, in which the social factor, in terms of weighting coefficients, is added. In Section IV the results from all strategies is summarized. In addition discussion regarding the technology selection is carried out. Finally in Section V the conclusions are made.

\section{Manufacturing Problem - Assemble of A HYDRAULIC GEAR PUMP}

In this paper as a benchmark example the mass produced gear hydraulic pump with a flow rate $0.25 \mathrm{~m}^{3} / \mathrm{h}$, operating pressure $-1.6 \mathrm{MPa}$, nominal speed of $1450 \mathrm{~min}^{-1}$, delivered power $0.33 \mathrm{KW}$ and weighing $1.5 \mathrm{~kg}$ is considered. The complete technical documentation in $2 \mathrm{D}$ and $3 \mathrm{D}$ has been developed in [3]. There it is proposed a network model from which a multitude of 436 structural variants for assembly of the device were obtained. Then this number was reduced by adopting limits for the number of operators working on the assembly line - not greater than three and the workplaces area - not greater than $4 \mathrm{~m}^{2}$. At the end the structural variant that minimize the assembly time of a device has been chosen. In [4] possible technological variants for device assembly according to criteria: lower costs, incurred during the production cycle are analysed. As a result from this analysis the technological variants have been further reduced to three: technology $\mathrm{V}_{1}$ - manual assembly with 12 components which involves three operators, working for three minutes each work duration $\mathrm{f}\left(\mathrm{x}_{1}\right)=0.15 \mathrm{~h}\left(3 \mathrm{~min}\right.$.); technology $\mathrm{V}_{2}-\mathrm{a}$ modular assembly (requires a re-design and integration of parts) with nine components, two operators working for two minutes each - work duration value $\mathrm{f}\left(\mathrm{x}_{2}\right)=0.067 \mathrm{~h}(2 \mathrm{~min}$.); technology $\mathrm{V}_{3}$ - automated assembly with six components, 
an assembly robot type SCARA is needed. During the operation a single operator and for one minute is enough $f\left(x_{3}\right)=0.017 \mathrm{~h}(1 \mathrm{~min}$.). It required time for each technology are obtained in [3]. For the respective technologies the initial material costs are: $M_{1}=500 €-$ the cost of basic equipment (tables, chairs, tools) in technology $\mathrm{V}_{1} ; \mathrm{M}_{2}=2000 €$ - there is added cost of re-design of the product necessary for technology $\mathrm{V}_{2} ; \mathrm{M}_{3}=4500 €-$ the added cost for purchase of a high-tech assembly robot for technology $V_{3}$. Not completely known at the time of the assembly technology selection are: $\mathrm{P}_{1}$ - labour costs (salaries and benefits) per operator per hour. It is known that they are in the range: $\mathrm{P}_{1}=10 \div 12 € / \mathrm{h} ; \mathrm{P}_{2}-$ number of orders for assembly products. It is expected they will be in between: $\mathrm{P}_{2}=2500 \div 10000$ units.

In Table I the possible combinations $\Theta_{i, j}=1,2,3,4,5$ of uncertain parameters values $\mathrm{P}_{1}$ and $\mathrm{P}_{2}$ are shown as follows: the first four combinations are derived from the boundaries and the last one is based on the average values of both uncertain parameters $\left(\mathrm{P}_{1 \mathrm{mid}}\right.$ and $\left.\mathrm{P}_{2 \mathrm{mid}}\right)$. The calculations of the cost matrix (according to (1)), for each technology and parameter's combinations are presented in Table I (for the benchmark example). They are input data for considered optimization strategies. Through application of the proposed in this paper criterion (objective function in the optimization) a performance index for each technology and uncertain parameter combination is computed. In the following tables a new column "rank" is introduced. In it the analysed technologies are arranged according to the chosen preference. There, "1" corresponds to the preferred technology. This indicator is important for the technology selection summary, which will be carried out at the end of the paper, where comparative analysis is performed.

\section{OPTIMIZATION STRATEGIES}

\section{A. Bayesian-Laplace Strategy.}

Based on the algorithm presented in [1], [2], [12], [13] and the proposed modification in the optimization criteria, the average cost in equal probability of all combinations of uncertain parameters are calculated. According to this modified strategy technology $\mathrm{V}_{\mathrm{i}}$ which corresponds to the minimum average estimated production costs is selected. For the studied case (hydraulic pump) the determination of optimal alternative is performed according to (2) and the results are presented in Table II. As a result from the implementation of this strategy the technology $V_{2}$ was obtained as the optimal one.

TABLE I: COST MATRIX

\begin{tabular}{|c|c|c|c|c|c|}
\hline & $\Theta_{1}$ & $\Theta_{2}$ & $\Theta_{3}$ & $\Theta_{4}$ & $\Theta_{5}$ \\
\hline $\mathrm{P}_{1}$ & $\mathrm{P}_{1 \text { min }}$ & $\mathrm{P}_{1 \min }$ & $\mathrm{P}_{1 \text { max }}$ & $P_{1_{\text {max }}}$ & $P_{1 \text { mid }}$ \\
\hline $\mathrm{P}_{2}$ & $\mathrm{P}_{2 \min }$ & $\mathrm{P}_{2 \max }$ & $\mathrm{P}_{2 \min }$ & $P_{2 \text { max }}$ & $\mathrm{P}_{2 \text { mid }}$ \\
\hline $\mathrm{V}_{1}$ & 1.70 & 1.55 & 2.00 & 1.85 & 1.70 \\
\hline $\mathrm{V}_{2}$ & 1.47 & 0.87 & 1.60 & 1.00 & 1.05 \\
\hline $\mathrm{V}_{3}$ & 1.97 & 0.62 & 2.00 & 0.65 & 0.90 \\
\hline
\end{tabular}

TABLE II: BAYESIAN-LAPLACE STRATEGY

\begin{tabular}{ccccccccc}
\hline \hline & $\Theta_{1}$ & $\Theta_{2}$ & $\Theta_{3}$ & $\Theta_{4}$ & $\Theta_{5}$ & $\Sigma \mathrm{C} / 5$ & rank & $\mathrm{V}_{\text {opt }}$ \\
\hline $\mathrm{V}_{1}$ & 1.70 & 1.55 & 2.00 & 1.85 & 1.70 & 1.766 & 3 & \\
$\mathrm{~V}_{2}$ & 1.47 & 0.87 & 1.60 & 1.00 & 1.05 & 1.198 & 1 & $\mathrm{~V}_{2}$ \\
$\mathrm{~V}_{3}$ & 1.97 & 0.62 & 2.00 & 0.65 & 0.90 & 1.228 & 2 & \\
\hline \hline
\end{tabular}

$$
V_{o p t} \rightarrow \min _{V_{i}} \sum_{j=1}^{5} \frac{C_{i, j}\left(V_{i}, \Theta_{j}\right)}{5}
$$

From Table II can be seen that technology $V_{3}$ is very close in terms of optimal indicator, i.e. that $\mathrm{V}_{2}$ and $\mathrm{V}_{3}$ have similar production indicators and thus the production costs of technology $V_{3}$ will not be much bigger than $V_{2}$.

For instance, increase in the production volume, or rise of the salaries can result in situation where technology $V_{3}$ will be preferable.

\section{B. Favourable Circumstances Strategy.}

Using the corresponding strategy presented in [1], [2], [17] the technology that provides minimal cost under the most favourable circumstances is selected. Note that the proposed change in the optimization criteria with cause corresponding change in the logic of the strategy. In this situation the criterion for determining the optimal alternative is presented in (3) and the calculated results from the implementation of this strategy are presented in Table III.

$$
V_{o p t} \rightarrow \min _{V_{i}} \min _{\Theta_{j}}\left\{C_{i, j}\left(V_{i}, \Theta_{j}\right)\right\}
$$

As a result from the application of this strategy it can be concluded that in this instance the technology $\mathrm{V}_{3}$ should be selected as optimal. It has the highest productivity. The optimal result is obtained in combination $\Theta_{2}$ of the uncertainty parameters which has a minimum hourly wages and maximum quantity of production. It should be taken into account that this is the perfect circumstances. This conclusion corresponds with the name of the strategy.

\section{Unfavourable Circumstances Strategy.}

According to references [1], [2], [17] and the proposed modification of the optimization criteria (also required change in the strategy logic), this strategy boils down to a search for technology that provides minimal production costs in the most unfavourable circumstances (pessimistic strategy). In this case the proposed calculation function for determining of the optimal technology is presented in (4). The calculated results for the discussed case study are presented in Table IV.

$$
V_{o p t} \rightarrow \min _{V_{i}} \max _{\Theta_{j}}\left\{C_{i, j}\left(V_{i}, \Theta_{j}\right)\right\}
$$

From the table it can be seen that the worst case scenario is with parameter combination $\Theta_{3}-$ minimal production quantity and maximal employee wage. In this unfavourable production situation the technology $V_{2}$ is obtained to be with the lowest cost. In this technology significant initial investment is avoided in comparison to the purchase cost and commissioning into service of the robot. The disadvantage of this approach is increase of the time for fulfilling orders due to lower productivity.

TABLE III: STRATEGY UNDER FAVOURABLE CIRCUMSTAN
\begin{tabular}{cccccccccc}
\hline & $\Theta_{1}$ & $\Theta_{2}$ & $\Theta_{3}$ & $\Theta_{4}$ & $\Theta_{5}$ & $\min \mathrm{C}$ & rank $\mathrm{V}_{\text {opt }}$ \\
\hline $\mathrm{V}_{1}$ & 1.70 & 1.55 & 2.00 & 1.85 & 1.70 & 1.55 & 3 \\
$\mathrm{~V}_{2}$ & 1.47 & 0.87 & 1.60 & 1.00 & 1.05 & 0.87 & 2 & \\
$\mathrm{~V}_{3}$ & 1.97 & 0.62 & 2.00 & 0.65 & 0.90 & 0.62 & 1 & $\mathrm{~V}_{3}$ \\
\hline \hline
\end{tabular}

TABLE IV: UNFAVOURABLE CIRCUMSTANCES STRATEGY

\begin{tabular}{ccccccccc}
\hline \hline & $\Theta_{1}$ & $\Theta_{2}$ & $\Theta_{3}$ & $\Theta_{4}$ & $\Theta_{5}$ & \multicolumn{2}{c}{$\max \mathrm{C}$ rank } & $\mathrm{V}_{\text {opt }}$ \\
\hline $\mathrm{V}_{1}$ & 1.70 & 1.55 & 2.00 & 1.85 & 1.70 & 2.00 & 2 & \\
$\mathrm{~V}_{2}$ & 1.47 & 0.87 & 1.60 & 1.00 & 1.05 & 1.60 & 1 & $\mathrm{~V}_{2}$ \\
$\mathrm{~V}_{3}$ & 1.97 & 0.62 & 2.00 & 0.65 & 0.90 & 2.00 & 2 & \\
\hline \hline
\end{tabular}




\section{Regret Strategy - Savage Strategy.}

Basing on the description presented in [1], [2], [14], [17] the cost matrix from Table $\mathrm{I}$ is transformed into a matrix of regret - Table V, where $r_{i, j}$ is the "regret" of the person making decision for taking not the best choice of technology in a particular combination $\left(\Theta_{\mathrm{j}}\right)$ of the uncertain parameters. Note that the proposed changes in the optimization criteria for this strategy will lead to change in the selection logic as well.

Production costs for each option $\mathrm{V}_{\mathrm{i}}$ are correlated with the minimum and maximum $\left(\mathrm{C}_{\min }\right.$ and $\left.\mathrm{C}_{\max }\right)$ which are derived from the costs matrix. The obtained optimization criteria for this instance is described with (5). For the benchmark example the results are presented in Table V.

$$
V_{o p t} \rightarrow \min _{i} \max _{j}\left\{r_{i, j} \rightarrow \frac{C_{i, j}-C_{\min }}{C_{\max }-C_{\min }}\right\}, r_{i, j}=\frac{C_{i, j}-0.62}{2-0.62}
$$

As a result from the application of this strategy the minimal regret is with technology $V_{2}$ and thus it is chosen as optimal one. This results are obtained for combination $\Theta_{3}-$ minimal number of manufactured units and a maximum operator's wage. This situation is unfavourable for production because the costs will be high which in term will reduce competitiveness and this can even lead to a jobs reduction.

\section{E. Framework Strategy - Hurwitz Strategy Without Weight Coefficients.}

Using the description shown in the literature [1], [2], [15] and the proposed changes in the optimization criteria for this strategy, each alternative $V_{i}$ is calculated. In order to do so the maximum and minimum operating costs $\left(\min \mathrm{C}_{\mathrm{i}, \mathrm{j}}\right.$ and $\max \mathrm{C}_{\mathrm{i}, \mathrm{j}}$ ) are determined and then their average value are taken. The calculations for determining the optimal technology are performed according to (6) and the result from the task in consideration are presented in Table VI.

$$
V_{\text {opt }} \rightarrow \min _{i} \overline{C_{i}}, \text { where } \overline{C_{i}}=\frac{\max _{j} C_{i j}+\min _{j} C_{i j}}{2}
$$

After calculations and application of the optimality criterion for optimal technology again the chosen technology is $\mathrm{V}_{2}$. According to this strategy production costs are minimal, but productivity is not the highest one (unlike technology $V_{3}$ ). As mentioned above the choice of technology $V_{2}$ would lead to decrease in the assembly efficiency which in turn will lead to increase of the production time per device (assembly of a pump). The social factors can be priority at a particular time, but it is not always suitable for long-term development of the plant.

\section{F. Hurwitz Strategy with Weight Coefficients.}

The idea of this strategy is also given in [1], [2], [15]. There it is proposed to apply weight coefficients, based on the priorities of the decision maker on pessimism and optimism. The goal is to overcome the reinsurance of selection of the most useful solution and to overcome complete pessimism.

TABLE V: REGRET STRATEGY

$\begin{array}{ccccccccccc}\Theta_{1} & \Theta_{2} & \Theta_{3} & \Theta_{4} & \Theta_{5} & \mathrm{r}_{1} & \mathrm{r}_{2} & \mathrm{r}_{3} & \mathrm{r}_{4} & \mathrm{r}_{5} & \max \mathrm{r} \text { rank } \mathrm{V}_{\mathrm{opt}}\end{array}$ \begin{tabular}{lllllllllllll}
\hline $\mathrm{V}_{1}$ & 1.70 & 1.55 & 2.00 & 1.85 & 1.70 & 0.78 & 0.67 & 1.00 & 0.89 & 0.80 & 1.00 & 2
\end{tabular} $\begin{array}{llllllllllllll}\mathrm{V}_{2} & 1.47 & 0.87 & 1.60 & 1.00 & 1.05 & 0.61 & 0.18 & 0.71 & 0.27 & 0.31 & 0.71 & 1 & \mathrm{~V}_{2}\end{array}$ $\begin{array}{lllllllllllll}\mathrm{V}_{3} & 1.97 & 0.62 & 2.00 & 0.65 & 0.90 & 0.97 & 0.00 & 1.00 & 0.02 & 0.20 & 1.00 & 2\end{array}$
TABLE VI: HURWITZ STRATEGY WITHOUT WEIGHT COEFFICIENTS

\begin{tabular}{ccccccccccc}
\hline \hline & $\Theta_{1}$ & $\Theta_{2}$ & $\Theta_{3}$ & $\Theta_{4}$ & $\Theta_{5}$ & $\min \mathrm{C} \max \mathrm{C}$ & $\overline{\mathrm{C}}$ & $\operatorname{rank}$ & $\mathrm{V}_{\text {opt }}$ \\
\hline $\mathrm{V}_{1}$ & 1.70 & 1.55 & 2.00 & 1.85 & 1.70 & 1.55 & 2.00 & 1.78 & 3 & \\
$\mathrm{~V}_{2}$ & 1.47 & 0.87 & 1.60 & 1.00 & 1.05 & 0.87 & 1.60 & 1.24 & 1 & $\mathrm{~V}_{2}$ \\
$\mathrm{~V}_{3}$ & 1.97 & 0.62 & 2.00 & 0.65 & 0.90 & 0.62 & 2.00 & 1.31 & 2 & \\
\hline \hline
\end{tabular}

The coefficients should comply with $0 \leq \alpha_{\mathrm{vi}} \leq 1$ and $\sum \alpha_{\mathrm{vi}}=1$.

$$
\begin{aligned}
& \min _{v_{i}} \bar{C}_{i}^{(\alpha)}= \\
& \min _{v_{i}}\left\{\alpha_{v_{i}} \min _{\theta_{j}}\left[C\left(V_{i}, \theta_{j}\right)\right]+\left(1-\alpha_{v_{i}}\right) \max _{j}\left[C\left(V_{i}, \theta_{j}\right)\right]\right\}
\end{aligned}
$$

For this particular benchmark example they are chosen as $\alpha_{\mathrm{v} 1}=0.2, \alpha_{\mathrm{v} 2}=0.3, \alpha_{\mathrm{v} 3}=0.5$. Since the proposed in this paper optimization criterion is changed, following coefficients are required instead $1-\alpha_{\mathrm{v} 1}=0.8,1-\alpha_{\mathrm{v} 2}=0.7,1-\alpha_{\mathrm{v} 3}=0.5$. They are multiplied with the minimum and maximum production costs, presented in column 7 and 8 of Table VII. Determining the optimal alternative is carried out in accordance with (7).

By observing Table VII it can be concluded that for optimal technology should be chosen technology $V_{3}$. This result is favourable in respect of production parameters high productivity and lower cost of production. This should be expected because the preference coefficient of this technology is the greatest. It can be noted that even with these selected coefficients the technology $V_{2}$ is a slightly inferior of technology $\mathrm{V}_{3}$.

\section{G. Modification of the Bayesian-Laplace Strategy with a Social Element and Weight Coefficients.}

In this paper the main goal for proposing modifications to the strategies is to add a social element in the decision making process. This is relevant with trends in social programs of the strategy "Europe 2020". The goal of those modified strategies is through minimizing the costs of assembly to add an intension for possible preservation of jobs for qualified workers. This is economically justified if it is assumed that these skilled workers will be needed in the company at the near future. It is proposed to set a weight coefficient for each technology $\mathrm{V}_{\mathrm{i}}$, which reflects a desire to keep more workers. This is similar idea to the one presented in the previous strategy. Thus, the strategy with more workers would receive a smaller coefficient and therefore less weight in the criterion for optimization, since the proposed optimization criteria is minimum production costs. Based on the above-described Bayesian-Laplace strategy and by introducing additional weighting factors $\alpha\left(0 \leq \alpha_{\mathrm{vi}} \leq 1\right.$, so $\left.\Sigma \alpha_{\mathrm{vi}}=1\right)$. The optimal alternative is determined according to the criterion (8).

$$
V_{o p t} \rightarrow \min _{V_{i}} \sum_{j=1}^{5} \alpha_{v_{i}} \frac{C_{i, j}\left(V_{i}, \Theta_{j}\right)}{5}
$$

As technology $V_{1}$ is with most operators it coefficient $\left(\alpha_{\mathrm{vi}}\right)$ must be at smallest. The next priority is for technology $V_{2}$, and the last is a technology $\mathrm{V}_{3}$. In case where the goal is to preserve the jobs of qualified operator's weightings have the following meaning: level relative to relevant technology corresponds to the readiness of the decision maker to provide the necessary additional funds in order to maintain the appropriate number of jobs in the plant.

For this case the selected values of weights are: for technology $\mathrm{V}_{1}$ (preserve is 3 jobs) $\alpha_{\mathrm{v} 1}=1 / 2=50 \%$; 
TABLE VII: HURWITZ STRATEGY WITH WEIGHT COEFFICIENTS

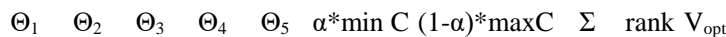

\begin{tabular}{lllllllllll}
\hline $\mathrm{V}_{1}$ & 1.70 & 1.55 & 2.00 & 1.85 & 1.70 & 0.31 & 1.60 & 1.93 & 3 & \\
$\mathrm{~V}_{2}$ & 1.47 & 0.87 & 1.60 & 1.00 & 1.05 & 0.26 & 1.14 & 1.40 & 2 & \\
$\mathrm{~V}_{3}$ & 1.97 & 0.62 & 2.00 & 0.65 & 0.90 & 0.31 & 1.00 & 1.31 & 1 & $\mathrm{~V}_{3}$ \\
\hline \hline
\end{tabular}

TABLE VIII: STRATEGY WITH SOCIAL ELEMENT AND WEIGHT COEFFICIENT

\begin{tabular}{cccccccccc} 
& $\Theta_{1}$ & $\Theta_{2}$ & $\Theta_{3}$ & $\Theta_{4}$ & $\Theta_{5}$ & $\sum \frac{\boldsymbol{C}_{\boldsymbol{i}, j}\left(\boldsymbol{V}_{\boldsymbol{i}}, \boldsymbol{\Theta}_{\boldsymbol{j}}\right)}{\mathbf{5}}$ & $\boldsymbol{\alpha}_{\boldsymbol{v}_{\boldsymbol{i}}} * \sum \frac{\boldsymbol{C}_{\boldsymbol{i}, \boldsymbol{j}}\left(\boldsymbol{V}_{\boldsymbol{i}}, \boldsymbol{\Theta}_{\boldsymbol{j}}\right)}{\mathbf{5}}$ & rank $\mathrm{V}_{\mathrm{opt}}$ \\
\hline $\mathrm{V}_{1}$ & 1.70 & 1.55 & 2.00 & 1.85 & 1.70 & 0.353 & 1.766 & 1 & $\mathrm{~V}_{1}$ \\
$\mathrm{~V}_{2}$ & 1.47 & 0.87 & 1.60 & 1.00 & 1.05 & 0.359 & 1.198 & 2 & \\
$\mathrm{~V}_{3}$ & 1.97 & 0.62 & 2.00 & 0.65 & 0.90 & 0.614 & 1.228 & 3 & \\
\hline \hline
\end{tabular}

for technology $V_{2}$ (preserve is 2 jobs) $\alpha_{\mathrm{v} 2}=1 / 3=33 \%$; for technology $V_{3}$ (preserve is 1 job) $\alpha_{v 3}=1 / 6=17 \%$. Thus, the chosen weightings are the following: $\alpha_{\mathrm{v} 1}=0.2, \alpha_{\mathrm{v} 2}=0.3$, $\alpha_{\mathrm{v} 3}=0.5$. The obtained results from the calculations are summarized in Table VIII. As a result of the modified Bayesian-Laplace strategy turns out that the choice of technology $\mathrm{V}_{1}$ is chosen as an optimal one. In this case, it is taken into account the social factor and as a result the maximum number of employees are retained.

In the Bayesian-Laplace strategy (without taking into account weighting factors) for optimal technology was obtained $\mathrm{V}_{2}$. Analysing the results of application of the optimality criterion for each technology indicate that even with the implementation of the modified strategy the resulting indexes for technologies $\mathrm{V}_{1}$ and $\mathrm{V}_{2}$ are pretty close. This is indicative that the choice of technology $V_{1}$ does not lead to large reductions in productivity. This difference is the smallest one in comparison with all other strategies. At the same time, the assembly cycle of a pump for the two technologies is similar.

\section{H. Modification of the Bayesian-Laplace Strategy with a Social Element and Additional Funding.}

One additional modification of the strategy is proposed. The optimality criterion of the original Bayesian-Laplace strategy (with proposed changes in the criterion) will remain the same, i.e. optimal technology is that a minimum average estimated costs.

A further condition is that the company can expect outside funding: for example: unemployment fund, for development of underdeveloped areas (e.g. - transporting workers from undeveloped areas to work in industrial enterprise in need of their skills) or labour costs - $\mathrm{P}_{1}$ (e.g. - salary and benefits) for one or more temporary workers. The optimization criteria is described with (9).

$$
V_{o p t} \rightarrow \min _{V_{i}} \sum^{5} \frac{C_{i, j}\left(V_{i}, \Theta_{j}\right)}{5}
$$

In Table $\mathrm{X}$ it is taken into account that maximum two workers are employed with full financing from an external funds (note that unexperienced workers will perform their tasks slower and also some additional initial training is required. Also, it can be expected reduction in the quality of the product. This factors are not taken into account in this investigation). The very important condition is that at least one worker in the team has a permanent employment contract with the company. This is relevant with the parameters of the technology $V_{1}$, because for the realization of this particular technology are employed three operators. External full or partial funding decreases labour component in the production cost for this technology and the start-up costs are minimal.
TABLE IX: STRATEGY WITH SOCIAL ELEMENT AND ADDITIONAL FUNDING

\begin{tabular}{lcccccccc} 
& $\Theta_{1}$ & $\Theta_{2}$ & $\Theta_{3}$ & $\Theta_{4}$ & $\Theta_{5}$ & \multicolumn{2}{c}{$\frac{c_{i, j}\left(V_{i}, \Theta_{j}\right)}{5}$} & rank \\
\hline $\mathrm{V}_{1}$ & 1.70 & 1.55 & 2.00 & 1.85 & 1.70 & 0.646 & 1 & $\mathrm{~V}_{1}$ \\
$\mathrm{~V}_{2}$ & 1.47 & 0.87 & 1.60 & 1.00 & 1.05 & 1.198 & 2 & \\
$\mathrm{~V}_{3}$ & 1.97 & 0.62 & 2.00 & 0.65 & 0.90 & 1.228 & 3 & \\
\hline \hline
\end{tabular}

TABLE X: TEMPORARY UNFAVOURABLE CIRCUMSTANCES

\begin{tabular}{ccccccccc}
\hline \hline & $\Theta_{1}$ & $\Theta_{2}$ & $\Theta_{3}$ & $\Theta_{4}$ & $\Theta_{5}$ & $(1-\alpha) \operatorname{maxC}$ & rank $\mathrm{V}_{\text {opt }}$ \\
\hline $\mathrm{V}_{1}$ & 1.70 & 1.55 & 2.00 & 1.85 & 1.70 & 1.00 & 1 & $\mathrm{~V}_{1}$ \\
$\mathrm{~V}_{2}$ & 1.47 & 0.87 & 1.60 & 1.00 & 1.05 & 1.07 & 2 & \\
$\mathrm{~V}_{3}$ & 1.97 & 0.62 & 2.00 & 0.65 & 0.90 & 1.66 & 3 & \\
\hline \hline
\end{tabular}

That corresponds to reduction of the cost of the final product. This could lead to expansion of the markets for this particular product, but it is useful only in the short term because funding from external sources is provided just for a limited period of time.

\section{Modification Strategy under Temporary Unfavourable Circumstances Strategy}

In this paper a modification of the unfavourable circumstances strategy is proposed by introducing the same weight coefficients as strategy $\mathrm{G}$. The determination of the optimal situation is carried out according to (10) and the calculated results are presented in Table X.

$$
V_{o p t} \rightarrow \min _{V_{i}}\left(1-\alpha_{v i}\right) \max _{\Theta_{j}}\left\{C_{i, j}\left(V_{i}, \Theta_{j}\right)\right\}
$$

As can be seen the great importance is payed to the social factors, which is evident from the weighting coefficients $\alpha_{\mathrm{vi}}$. According to this optimality criterion technology $\mathrm{V}_{1}$ is chosen as optimal. This modification is related to jobs preservation in the plant which would satisfy the demands of employees and Trade Unions. This is going to reduce the plant's profits, will hold back its modernization and harm the production efficiency. This technology has significant advantages in a short-term production, because it will keep qualified workers which will increase capacity for development of the plant in the future. According to (1) (in inverse proportional relation between $\mathrm{C}$ and $\mathrm{P}_{2}$ ) calculated above cost matrix has a correlation between unfavourable circumstances with low orders volume for the assembly product. In case of single units production even the cost for redesigning of the product can be avoided by application of technology $\mathrm{V}_{1}$. However, in this case the production time will be further increased. On the other hand this situation could be a dangerous in aspect of shrink production that can lead to reduction of jobs and turnover of qualified operators. If there are suggestions that these adverse circumstances are temporary (possibly out of the crisis) a thought can be given in regard to a new or modified strategy which takes into account the wishes of employers and/or Trade Unions to keep qualified workers. In order to achieve this, some funds from the company should be dedicated - e.g. at the expense of less profit to allow for partial coverage of total costs - for the considered technologies.

\section{ANALYSIS OF THE RESUltS}

In this section a comparative analysis of the various strategies implementation is carried out. Similar comparison is proposed in [1]. For the investigated system (hydraulic 
gear pump) the data is presented on Table XI. For each strategy the optimal choice is presented.

TABLE XI: RESULTS OF STRATEGIES

\begin{tabular}{|c|c|c|c|c|}
\hline Strategy & $\mathrm{V}_{\mathrm{opt}}$ & $\begin{array}{c}\text { cost in } \\
\text { real case } \\
\Theta_{1}\end{array}$ & $\begin{array}{c}\text { cost in the } \\
\text { best case } \\
\Theta_{1}-\Theta_{2}\end{array}$ & $\begin{array}{c}\text { cost in the } \\
\text { worst case } \\
\Theta_{1}-\Theta_{3}\end{array}$ \\
\hline $\mathrm{S}_{1}$ & $\nabla_{2}$ & 1.40 & 0.60 & -0.12 \\
\hline $\mathrm{S}_{2}$ & $\mathrm{~V}_{3}$ & 1.90 & 1.35 & -0.02 \\
\hline $\mathrm{S}_{3}$ & $\mathrm{~V}_{2}$ & 1.40 & 0.60 & -0.12 \\
\hline $\mathrm{S}_{4}$ & $\mathrm{~V}_{2}$ & 1.40 & 0.60 & -0.12 \\
\hline $\mathrm{S}_{5}$ & $\mathrm{~V}_{2}$ & 1.40 & 0.60 & -0.12 \\
\hline $\mathrm{S}_{6}$ & $\mathrm{~V}_{3}$ & 1.90 & 1.35 & -0.02 \\
\hline
\end{tabular}

The production costs are determined by the costs matrix for assembly of a single device. In this particular case, a situation where uncertain parameters are in the middle of their ranges is considered (combination $\Theta_{5}$ ). After observation of Table XI it can be concluded that the technology $V_{1}$ has a definite advantage over other technologies in the case when the social factor is form great importance for the decision making person. However, especially for long term production, its economic indicators are weaker in comparison to other technologies. This is especially true for large-scale production.

The technology $V_{2}$ is considered as optimal for the largest number of the investigated strategies. This is evidence for the versatility of this strategy (satisfy a wider range of different criteria). Thus, its selection is the most obvious choice. This strategy should be considered as a primal strategy.

As it can be seen from the Table XI, the technology $V_{3}$ is optimal in a small number of cases, but its results are superior in comparison to the other technologies efficiency. It should be considered when the number of produced units is large and/or the wages are high.

\section{CONCLUSION}

In this paper the task for technology selection is examined. The results are demonstrated on a benchmark example: assembly of a mechanical device - gear hydraulic pump. The investigated strategies are for optimization in the presence of uncertainty and final number of possible technologies. As a main optimization criterion the minimization of the costs for labour and equipment for assembling the device is considered. The implementation of the various strategies for the example is presented as well. The results are discussed as well.

Three modified strategies involving certain social elements that are the relevant with the social trends of the strategy "Europe 2020" are proposed in this paper in addition to standard strategies.

A comparative analysis of results obtained from the implementation of all strategies for optimization is prepared at the end. The conclusion about the strategy selection is carried out.

\section{REFERENCES}

[1] S. Stoyanov, Optimization of Technological Processes, 1st ed. Sofia: Technica, 1993.

[2] S. Stoyanov, "Methods and algorithms for optimization under incomplete information, lectures at Technical University of Gabrovo," 2013

[3] G. Dinev, I. Malakov, D. Docev, and L. Baltova, Selection of options for assembly of mechanical product," Journal of Mechanical Engineering and Mechanical Science, vol. 10, no. 1, pp. 12-16, 2010.
[4] A. Ichtev and L. Baltova, "Preliminary graph analytical analysis for selection of assembly technology for mechanical devise under uncertainties," in Proc. of Technical University-Sofia, vol. 65, no. 1, pp. 365-372, 2015.

[5] H. Gaspars-Wieloch, "On a decision rule for mixed strategy searching under uncertainty on the basis of the coefficient of optimism," Elsevier Ltd., 2013.

[6] F. Klocke, K. Arntz, and D. Heeschen, "Decision-making process in manufacturing technology planning for small scale productions," in Proc. 47th Hawaii International Conference on System Science, pp. $836-845,2014$.

[7] N. Ben Abdallah, S. Destercke, and M. Sallak. (2016). Easy and optimal queries to reduce set uncertainty. European Journal of Operational Research. [Online]. Available: http://dx.doi.org/10.1016/j.ejor.2016.06.038

[8] M. Basili, A. Chateauneuf, and F. Fontini, "Precautionary principle as a rule of choice with optimism on windfall gains and pessimism on catastrophic losses," Ecological Economics, vol. 67, pp. 485-491, 2007.

[9] R. Sanchez, "Integrating Transaction Costs Theory and Real Options Theory," Managerial and Decision Economics, vol. 24, no. 4, pp. 267-282, June 2003.

[10] O. A. Yemetsa and N. Y. Ustiana, "Games with combinatorial constraints, cybernetics and systems analysis," vol. 44, no. 4, 2008.

[11] Q. Y. Yan, Q. Zhang, and X. Zou. (2016). A cost optimization model for multiresource leveling problem without project duration constraint. Discrete Dynamics in Nature and Society. [Online]. 2016. Available: http://dx.doi.org/10.1155/2016/1514959 Hindawi Publishing Corporation

[12] F. T.-C. Tsai, "Bayesian model averaging assessment on groundwater management under model structure uncertainty," Stoch Environ Res Risk Assess, vol. 24, pp. 845-861, 2010.

[13] P. C. Leube, A. Geiges, and W. Nowak, "Bayesian assessment of the expected data impact on prediction confidence in optimal sampling design," Water Resources Research, vol. 48, 2012.

[14] E. Conde, A minmax regret linear regression model under uncertainty in the dependent variable, J Optim Theory Appl, vol. 160, pp. 573-596, 2014.

[15] K. Peleckis, "The use of game theory for making rational decisions in business negotiations: a conceptual model," Entrepreneurial Business and Economics Review, vol. 3, no. 4, pp. 105-121, 2015.

[16] V. V. Malyshev, B. S. Piyavsky, and S. A. Piyavsky, "A decision making method under conditions of diversity of means of reducing uncertainty, systems analysis and operations research," Journal of Computer and Systems Sciences International, vol. 49, no.1, pp. 44-58, 2010.

[17] P. Thipwiwatpotjana, W. A. Lodwick, "Pessimistic, optimistic, and minimax regret approaches for linear programs under uncertainty," Fuzzy Optim Decis Making, vol. 13, pp. 151-171, 2014.

[18] Kann, Antje, Weyant, and P. John, "Approaches for performing uncertainty analysis in large-scale energy/economic policy models," Environmental Modeling \& Assessment, vol. 5, no. 1, pp. 29-46, 2000.

[19] V. A. Masch, "Extensions of stochastic multiscenario models for long-range planning under uncertainty," Environ Syst Decis, vol. 33, pp. 43-59, 2013.

[20] B. Tarhan, I. E. Grossmann, and V. Goel, "Computational strategies for non-convex multistage MINLP models with decision-dependent uncertainty and gradual uncertainty resolution," Ann Oper Res, vol. 203, pp. 141-166, 2013.

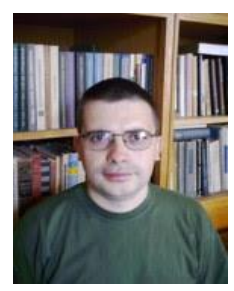

Alexandar K. Ichtev was born in Sofia, Bulgaria. In 1999 he graduated from the Technical University of Sofia as an engineer in automatic control. From 1999 to 2001 he carried out half of his Ph.D research in Delft, The Netherlands. He received Ph.D. degree from the Technical University of Sofia in 2004 after an obligatory military service (2003). From 2004 he is assistant professor at the Technical University of Sofia, Department of Systems and Control Engineering. Since 2008 he is associate professor at the same department. From 2011 till 2014 he was vice dean of the faculty of Automatics. His scientific interests are in the field of classical control systems, fault detection and isolation (FDI), fault tolerant control (FTC), fuzzy control, adaptive control and robust control.

Lyudmila I. Baltova is a teacher at the Technical University of Sofia, the Faculty of Mechanical Engineering, the Department of Fundamentals and Technical Means of Design. 